\title{
Structural and Morphological Studies of Lava Rock from Mount Gamalama Ternate for Possible Functional Materials Applications
}

\author{
Malik Anjelh Baqiya, ${ }^{1, *}$ Iqbal Limatahu, ${ }^{2}$ Muhammad Nasrun, ${ }^{2}$ and Darminto ${ }^{1}$ \\ ${ }^{I}$ Department of Physics, Faculty of Mathematics and Natural Sciences, \\ Institut Teknologi Sepuluh Nopember (ITS), Kampus ITS, Sukolilo, Surabaya, 61111 Indonesia \\ ${ }^{2} J u r u s a n$ Pendidikan Fisika, Fakultas Keguruan dan Ilmu Pendidikan, \\ Universitas Khairun, Kampus I Akehuda, Ternate, Maluku Utara, Indonesia
}

\begin{abstract}
A large eruption of Mount Gamalama happened nearly 350 years ago has left the frozen lava rocks that are now spread in the form of black stone located in the North-East coast of the island of Ternate, called batu angus (Angus stone). This paper reports the basic analysis including the phase content, crystal structure and particle morphology of the frozen lava rock, Angus stone, briefly. Based on the XRD pattern, Angus stone contains up to $20 \%$ of magnetic phases. The analysis of XRF and XRD data reveals that there are dominantly non-magnetic phases (silicate phases) in the Angus stone with the combination of Si-Al-K-Ca-O elements. Elemental distribution map from SEM/EDX image shows that there is a clear separation between non-magnetic and magnetic phases in the crushed powders indicating the easiness to obtain both phases separately. This study proves that Angus stone has potential application as a base material for the preparation of magnetic and non-magnetic functional materials.
\end{abstract}

KEYWORDS: Angus stone, Ternate, particle morphology, phase content http://dx.doi.org/10.12962/j24604682.v13i1.2134

\section{INTRODUCTION}

Many efforts have been paid to explore and study natural resources as the basic compounds for synthesizing advanced materials, especially for nanomaterials. Indonesia is one of many countries which has abundant natural resources, namely iron sand or iron ore, silica sand, zircon sand, and limestone. Iron sand consists of dominantly magnetite $\left(\mathrm{Fe}_{3} \mathrm{O}_{4}\right)$. It can be used for producing $\mathrm{Fe}_{3} \mathrm{O}_{4}$ nanoparticles [1, 2]. Further researches utilizing this $\mathrm{Fe}_{3} \mathrm{O}_{4}$, it has been successfully synthesized $\mathrm{Fe}_{3} \mathrm{O}_{4}$-based ferrofluid [3], PVA-based ferrogels [4], radar absorber materials [5], magnetic coating [1], and $\mathrm{BiFeO}_{3}$ as multiferroic materials [6, 7]. Micro- and nano- sized $\mathrm{CaCO}_{3}$ particles have also been investigated from the natural limestone [8, 9]. Moreover, silica and forsterite nanopowders have been successfully prepared from the silica sand $[10,11]$ and zircon sand [12], respectively.

Natural rocks or sand are usually composed of both various inorganic and organic minerals. Therefore, it is quite difficult to obtain nanoparticles with high purity sample. One way to achieve this is by performing chemical co-precipitation method. The advantage of this method is the ability to separate the unwanted compounds by dissolving and filtering techniques. Moreover, this method is very simple and the preparation time is quite short. This can reduce the production cost

*E-MAIL: malikabitsephysics.its.ac.id and suitable to be applied in countries having rich of natural resources. The use of surfactant and template for synthesizing $\mathrm{Fe}_{3} \mathrm{O}_{4}$ nanoparticles may influence their particle morphologies, size, and distribution. For instance, the structural and particles analysis of ferrofluid and ferrogel from iron sand has shown a good crystallinity with particle size of $8 \mathrm{~nm}$ without any impurity phase $[13,14]$. Furthermore, the dry method and hydrothermal synthesis have been employed to obtain crystalline silica powders with different polymorphs (quartz and crystobalite phases) [15].

Rocks made from lava usually consist of silicon, iron, aluminium, magnesium, calcium, sodium, and other minor elements. It needs separation technique to obtain the desired materials. Lava rocks from Mount Gamalama, called batu angus (Angus stone), have a physical color of deep-black. Powders of the stone have a unique property which can be attracted by permanent magnet when it is brought closer to the magnet. There are many other unwell-known physical properties that can be studied from the Angus stone. This paper tries to investigate the physical properties of the Angus stone from Mount Gamalama, Ternate, including the analysis of phase composition, crystal structure, and particle morphology as the basic study for further synthesis and applications.

\section{EXPERIMENTAL}

Batu Angus (Angus stone) derived from molten magma of Mount Gamalama, North-East of Ternate, was used as the test material. The stone was crashed to get powder form. The 


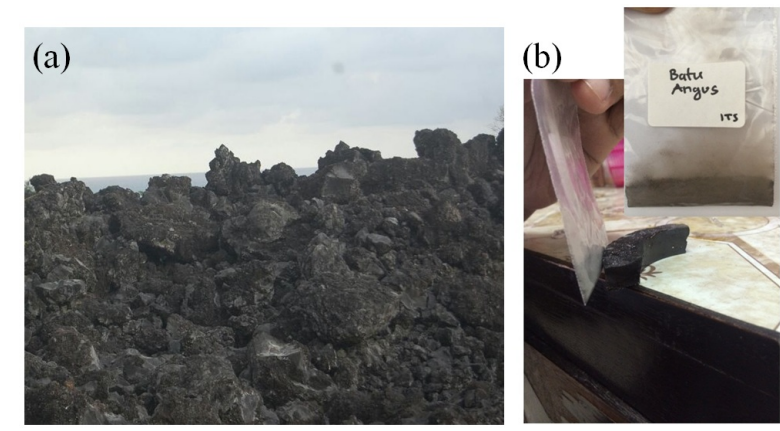

FIG. 1: (a). Angus stone area in the North-east coast of Ternate, (b). magnetic attraction between the powders of Angus stone and external permanent magnetic bar.

powder was then washed by distilled water and dried to obtain the dried powder form for further measurements and analysis. The dried powders of Angus stone were then characterized by x-ray fluorescence (XRF), x-ray diffractometry (XRD), dan scanning electron microscopy - energy-dispersive X-ray spectrometry (SEM-EDX). XRF measurements were used to figure out the existing elements and their percentage in the specimen. XRD measurements were performed to study the crystalline phase and phase composition in the specimen supported by the XRF data. The phase identification of the XRD pattern was analyzed by the commercial software called Crystal Impact Match!. By analyzing the intensity of each peak in the XRD pattern, the phase composition can be predicted by the Eq.(1). SEM-EDX measurements were conducted to investigate the morphology, size, and distribution of the dried specimen.

$$
\% \text { phase }=\frac{\Sigma I_{\text {peak phase }}}{\Sigma I_{\text {total peak }}} \times 100 \%
$$

where \%phase is the estimated phase percentage, SIpeak phase is the sum of all intensity peaks of the same phase, and $\Sigma$ Itotal peak is the sum of total intensity peaks.

\section{RESULTS AND DISCUSSION}

The magnetic behavior of the dried powders of Angus stone were firstly identified by taking them near permanent magnet. The result shows that the specimen powders were attracted by the magnet. However, the attractive magnetic force is relatively weak. It means that the Angus stone contains a portion of magnetic compounds, beside other non-magnetic compounds in the specimen. Figure 1(a) displays the real appearance of Angus stone in the North-East coast of the island of Ternate. It has a deep-black color and it is relatively easily to be crushed into powders. Figure 1(b) shows the attraction between powders of the Angus stone and the magnet permanent. Therefore, it is important to explore the phase content and the morphology of this Angus stone for determining possible advanced applications.

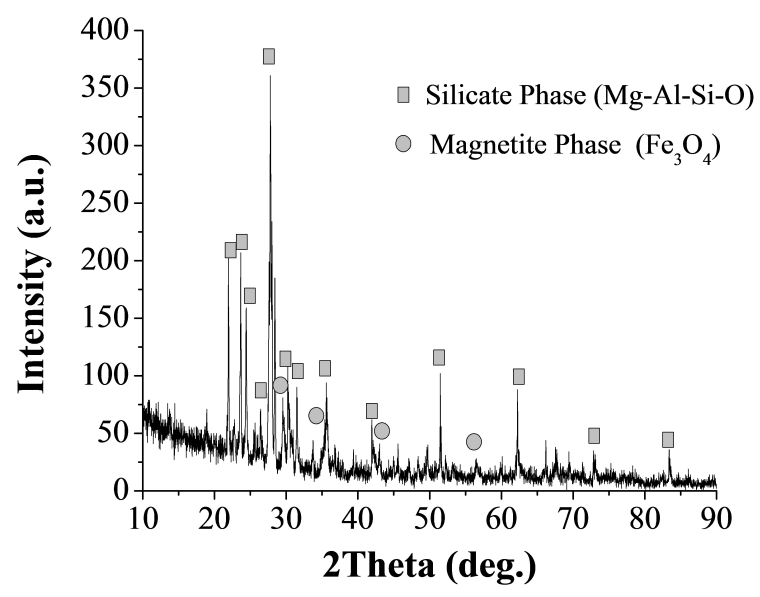

FIG. 2: X-ray powder diffractometry (XRD) pattern of the dried powders of Angus stone.

In order to analyze the correct phase content from XRD patterns, XRF measurements should be performed. Table I presents the XRF data of the dried powders of Angus stone showing the elemental content and its percentage in the specimen. It can be seen that Angus stone consists of several elements of $\mathrm{Fe}, \mathrm{Si}, \mathrm{Ca}, \mathrm{Al}, \mathrm{K}, \mathrm{Ti}$, and other minor elements. The element of Fe has the largest percentage of around 35\%. This explains the appearance of magnetic properties in Angus stone. However, this percentage is quite low compared to the other elements composed the Angus stone. This is the reason why the powders have weak magnetic attraction to the external permanent magnet. In addition, not all of $35 \%$ of Fe element will form the strong magnetic phase in the specimen. Hence, the XRD pattern of the powders must be analyzed carefully.

Figure 2 shows XRD pattern of the dried powders of Angus stone. Phase identification of this pattern reveals that the powders consist of dominantly silicate phases (i.e. anorthite and sanidine phases) built from $\mathrm{Si}-\mathrm{Al}-\mathrm{K}-\mathrm{Ca}-\mathrm{O}$ elements which are non-magnetic phases and magnetite $\left(\mathrm{Fe}_{3} \mathrm{O}_{4}\right)$ phase which is a magnetic phase. Based on the peak intensity analysis using Eq.(1), the percentage of silicate and $\mathrm{Fe}_{3} \mathrm{O}_{4}$ phases are around $80 \%$ and $10 \%$, respectively. The remaining magnetic elements, shown in Table I, combine each other to form other magnetic oxides in the specimen. However, they have a relatively weak magnetic behavior compared to $\mathrm{Fe}_{3} \mathrm{O}_{4}$ phase. This analysis shows that Angus stone has weak magnetic properties due to large amount of non-magnetic phases composing the stone.

In order to be applied as an advanced material, the nonmagnetic and the magnetic phases composing Angus stone should be separated by separation technique. Figure 3(a) and (b) show respectively the SEM and EDX images of the powder form of Angus stone crushed and grinded manually. Figure 3(a) points out that the powders have particle size of micrometer with various size, shapes, and a quite wide particle size distribution. This is due to the existence of various phases in the powders. The elemental distribution of the particles is represented in Figure 3(b). It reveals that there is a clear el- 
TABLE I: Element content and their composition in the powders of Angus stone measured by x-ray fluorescence sprectrocopy (XRF).

\begin{tabular}{lccccccccc}
\hline \hline Elements & $\mathrm{Fe}$ & $\mathrm{Si}$ & $\mathrm{Ca}$ & $\mathrm{Al}$ & $\mathrm{K}$ & $\mathrm{Ti}$ & $\mathrm{Ni}$ & $\mathrm{Mn}$ & Others \\
\hline Percentage (\%) & 35.2 & 28.0 & 19.1 & 8.6 & 3.4 & 2.0 & 0.9 & 0.7 & 2.1 \\
\hline \hline
\end{tabular}
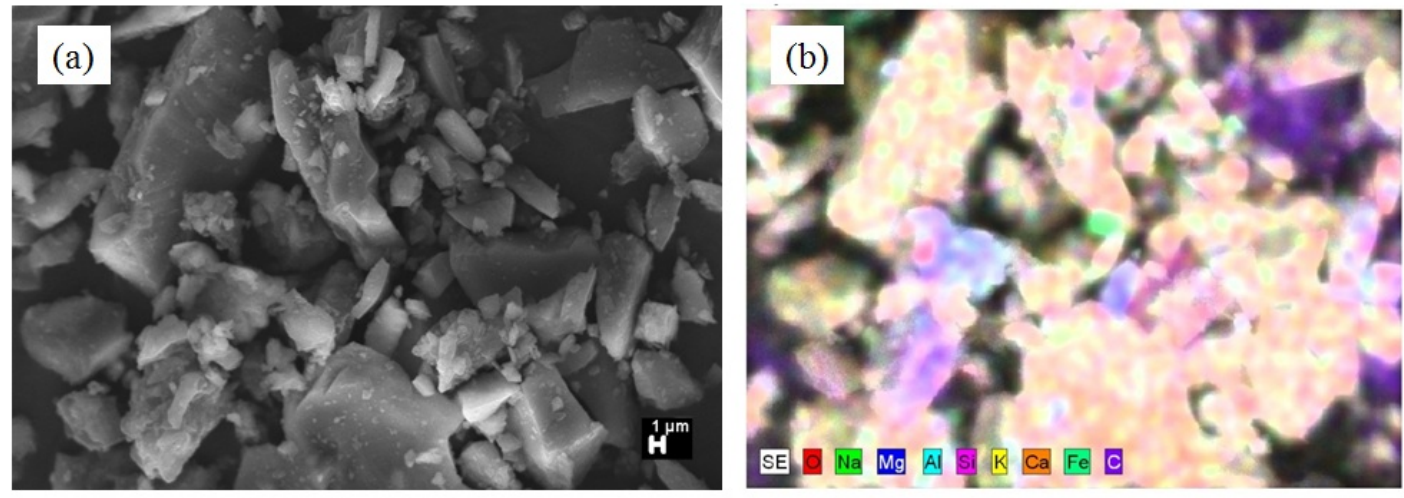

FIG. 3: (a) Scanning electron microscopy (SEM) and (b) energy-dispersive x-ray spectroscopy (EDX) images of the crashed powders of Angus stone.

emental separation between non-magnetic and magnetic particles in the crushed powders. This indicates the easiness to separate those phases. This is very important for further synthesis. Therefore, Angus stone has potential applications to be functional materials utilizing both magnetic and non-magnetic materials. However, it needs more studies for this purpose.

\section{SUMMARY}

Angus stone (batu angus) has relatively weak magnetic behavior because it has only up to $20 \%$ of magnetic phases. Sil- icate phases, the non-magnetic phases, are dominant in the dried powders of Angus stone. The elemental mapping from $\mathrm{SEM} / \mathrm{EDX}$ images shows a clear separation between magnetic and non-magnetic elements meaning that it is easy to obtain both phases with a simple separation technique. Therefore, it is concluded that Angus stone can be used as the basis compounds for preparation of functional materials employing both magnetic and non-magnetic phases.
[1] Triwikantoro, et al., Journal of Superconductivity and Novel Magnetism, 30, 555-560 (2017).

[2] Sunaryono, et al., Materials Science Forum, 827, 229-234 (2015).

[3] A. Taufiq, et al.,Materials Science Forum, 827, 213-218 (2015).

[4] Sunaryono, et al., Magneto-elasticity in hydrogels containing $\mathrm{Fe} 3 \mathrm{O} 4$ nanoparticles and their potential applications, AIP Conference Proceedings, 1555, 53-56, 2013.

[5] Mashuri, et al., Epoxy Resin Matrix Nanocomposites with CoreShell Structure of NiZnFerrite/Ag and NiZnFerrite/PANi as Fillers for Microwave Absorber in Kaband, AIP Conference Proceedings, 1415, 238-241, 2011.

[6] R. Asih, et al., Effect of Pb doping on multiphase coexistence and magneto-electric properties of bismuth ferrite, AIP Conference Proceedings, 1617, 26-29, 2014.

[7] R. Asih, M. Gufron, Darminto, Synthesis of (Pb,Ni)-doped $\mathrm{BiFeO}_{3}$ multiferroic systems via a sol-gel method and their magneto-electric properties, AIP Conference Proceedings, 1554, 50-53, 2013.
[8] Z. Arifin, et al., Analysis of $\mathrm{CaCO}_{3}$ products from lime solution, AIP Conference Proceedings, 1554, 90-92, 2013.

[9] Z. Arifin, et al., Transactions - Indian Ceramic Society, 74, 202207, 2015.

[10] Munasir,et al., Synthesis of silica nanopowder produced from Indonesian natural sand via alkalifussion route, AIP Conference Proceedings, 1555, 28-31, 2013.

[11] M. Khairanissa, et al., Synchrotron WAXS and XANES studies of silica $\left(\mathrm{SiO}_{2}\right)$ powders synthesized from Indonesian natural sands, Journal of Physics: Conference Series, 795, 012007, 2017.

[12] U. Nurbaiti, et al., Synthesis of nano-forsterite powder by making use of natural silica sand, AIP Conference Proceedings, 1710, 030037, 2016.

[13] A. Taufiq, et al., Journal of Superconductivity and Novel Magnetism, 28, 2855-2863, 2015.

[14] Sunaryono, et al., Nano, 11 (2016) 1650027.

[15] Munasir, et al., Materials Science-Poland, 33, 4755, 2015. 